\title{
Use of Surface Refractivity in the Empirical Prediction of Total Atmospheric Refraction
}

\author{
W. R. Iliff and J. M. Holt \\ Contribution from the Collins Radio Company, Cedar Rapids, Iowa
}

(Received August 10, 1962)

\begin{abstract}
The use of a 1.9-cm radio sextant capable of precise tracking of the sun has produced accurate measurements of total atmospheric microwave refraction. These data are used to verify the high correlation of such refraction with surface refractivity for low altitude angles. The values of the correlation coefficients obtained vary from 92.2 percent at 16 degrees to 98 percent at 2 degrees. An empirical predictor is developed, based on this correlation, which satisfactorily accounts for the observed refraction. The mathematical form of the predictor is given, and suggestions are made for its use.
\end{abstract}

\section{Introduction}

Theoretical investigations conducted by B. R Bean and B. A. Cahoon [1957] have indicated that total atmospheric microwave refraction can be predicted from observations of surface refractivity. Specifically, their proposed method of prediction requires that the total bending angle be linearly correlated with surface refractivity. That is, total atmospheric microwave refraction $(\tau)$ can be calculated from an equation of the form

$$
\tau=b N_{S}+a
$$

where $N_{S}$ is surface refractivity and $b$ and $a$ are coefficients which are functions of observed altitude (elevation) angle.

The objectives of the analysis described in this article were to verify by experiment the utility of the prediction technique suggested by Bean and Cahoon for discrete low altitude angles and to extend their analysis by developing suitable empirical formulas for the evaluation of the parameters $a$ and $b$ for arbitrary values of altitude angle.

This experiment was made possible by the recent development at Collins Radio Company of a 1.9-cm radio sextant capable of precise tracking of the sun. With this instrument, total atmospheric microwave refraction can be measured. The total bending angle is given by the difference between the observed position of the sun as determined by the radio sextant and the true position as derived from the solar ephemeris.

Thus, by simultaneously measuring the apparent altitude angle of the sun and the surface refractivity, it is possible to verify the linear correlation of refraction angle with surface refractivity.

\section{Collection and Preparation of Data}

Solar tracking data obtained from the radio sextant during the period from August through Decem- ber 1959 at a site near Cedar Rapids, Iowa, were available for the analysis. Most of the available data for altitude angles less than 20 degrees were used. Exceptions involved rejection of data when independent information indicated a malfunction of the equipment or rejection on the basis of intermittent or sparse low angle data. The data selected for further analysis included 35 sunsets and 14 sunrises.

The data for each of these 49 cases were corrected for predictable equipment errors. Corrections were made for Inductosyn gain-phase error and outer-loop bias. The dial index error, as determined from refraction-corrected, high-angle tracking data for the same day, was removed from the data for each sunrise and sunset [Anway, 1961].

The remaining difference between observed and true solar altitude angle was assumed to consist entirely of atmospheric refraction plus a random tracking error. In order to eliminate the random component and to permit evaluation of measured refraction at specific values of observed altitude angle, a polynomial was fitted by the method of least squares to each of the 49 refraction plots. Generally, a fifth-order polynomial was required to obtain a satisfactory fit over the pertinent range of observed altitude angles. In a few instances the polynomial was judged to be a poor representation of the initial refraction plot over a portion of its range because of gaps in the initial data or similar difficulties. These segments were rejected with as much objectivity as possible by assigning applicability ranges to the polynomials prior to further analysis. One sunset was eliminated completely in this manner, leaving 34 sunsets and 14 sunrises for further analysis.

It was assumed at this point that the polynomials, evaluated at any given altitude angle, would yield the best estimates of refraction, exclusive of any short-term refraction fluctuations which would have 
been smoothed out along with the random error. Hereafter, reference to the experimental values of refraction is understood to mean reference to the polynomial estimate of refraction. Figure 1 shows the mean and standard deviation of measured refraction at integral altitude angles from 2 to 16 degrees.

Values of surface refractivity were computed using the Smith and Weintraub equation [1953] which is valid throughout the microwave region.

$$
N=(n-1) 10^{6}=\frac{77.6}{T}\left[p+\frac{4810 e}{T}\right] .
$$

In $(2), n$ is the refractive index, $e$ is the partial pressure of water vapor in millibars, $p$ is the total pressure in millibars, and $T$ is the absolute temperature in degrees Kelvin.

Surface pressure, temperature, and wet bulb depression normally were measured every one-half hour during solar tracking. Thus, for each sunrise or sunset it was possible to associate a computed surface refractivity with each observed altitude angle. Because the changes in $N_{s}$ for successive observations generally were quite small, no interpolations between observations were considered necessary.

\section{Correlation}

Plotting the measured refraction against the associated surface refractivity at selected values of altitude angle produced scatter diagrams such as those shown in figure 2. A regression analysis was performed on the data of the scatter diagram for each integral altitude angle from 2 to 16 degrees. The intercept $a$ and slope $b$ for each regression line and

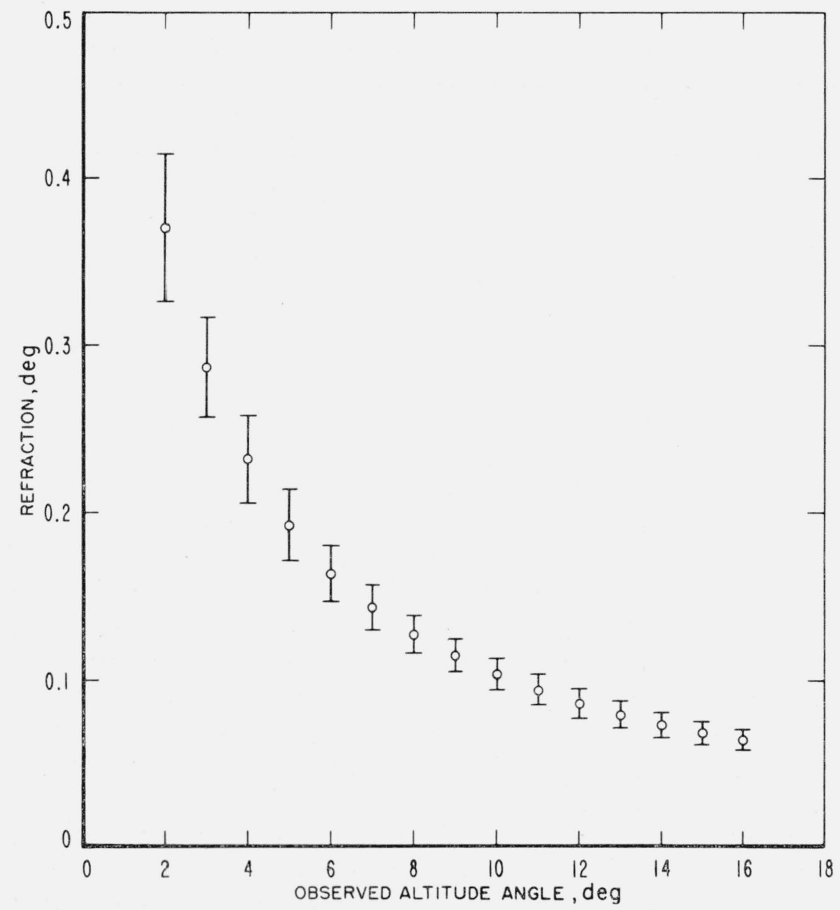

Figure 1. Mean and standard deviation of measured refraction other pertinent statistics are tabulated in table 1 .

The table indicates that the number of points used to determine each regression line varies from a minimum of 21 at an angle of 2 degrees to a maximum of 47 at angles of 13 degrees and 14 degrees. The smaller number of points at the lower values of altitude angle results from a scarcity of tracking data at those angles. In particular, no sunrise data were available below an observed altitude angle of about 5 degrees. On the other hand, at altitude angles of 13 degrees and 14 degrees, all but one of the 48 cases considered were applicable.

(Comments on the nature of the slopes and intercepts of the regression lines are deferred to the next section on the development of predictors.)

Without a correlation with $N_{S}$, a prediction of refraction equal to the mean refraction listed for each angle would result in the corresponding standard deviation or prediction uncertainty in the next column. Employment of the regression line of slope $b$ and intercept $a$, however, results in the standard deviation shown in the final column. The uncertainty is seen to be reduced in this manner by a factor varying roughly between 0.2 and 0.4 .

It is not implied that the relatively constant standard deviation about the regression lines for angles of 10 degrees or greater is the true uncertainty of refraction prediction in this region. It is probable that this standard deviation is the accuracy limit of the analysis techniques employed. Nonrandom components in the original error plots, discrepancies in the curve-fitting process, and errors in the estimation of surface refractivity certainly contribute significantly to this lower limit of the standard deviation about the prediction line.

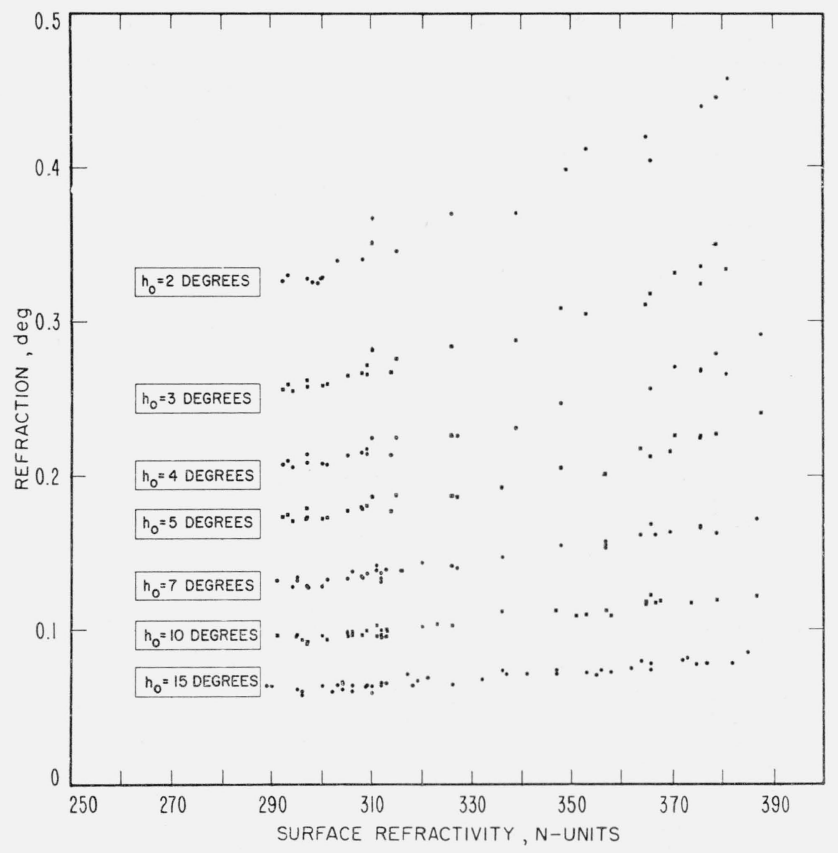

FIgURE 2. Scatter diagrams of measured refraction versus measured surface refractivity for selected observed altitude angles. 
TABLE 1

\begin{tabular}{|c|c|c|c|c|c|c|c|}
\hline $\begin{array}{c}\text { Ob- } \\
\text { served } \\
\text { altitude } \\
\text { angle }\end{array}$ & $\begin{array}{l}\text { Num- } \\
\text { ber of } \\
\text { data } \\
\text { points }\end{array}$ & $\begin{array}{l}\text { Mean } \\
\text { refrac- } \\
\text { tion }\end{array}$ & $\begin{array}{l}\text { Stand- } \\
\text { ard de- } \\
\text { viation } \\
\text { of re- } \\
\text { fraction }\end{array}$ & $\begin{array}{l}\text { Inter- } \\
\text { cept a }\end{array}$ & $\begin{array}{c}\text { Slope } \\
\text { b }\end{array}$ & $\begin{array}{l}\text { Correla- } \\
\text { tion co- } \\
\text { efficient }\end{array}$ & $\begin{array}{l}\text { Standard } \\
\text { deviation } \\
\text { about re- } \\
\text { gression } \\
\text { line }\end{array}$ \\
\hline $\begin{array}{c}\text { Degrees } \\
2 \\
3 \\
4 \\
5 \\
6\end{array}$ & $\begin{array}{l}21 \\
26 \\
26 \\
28 \\
33\end{array}$ & $\begin{array}{c}\text { De- } \\
\text { grees } \\
0.3696 \\
0.2867 \\
0.2316 \\
0.1933 \\
0.1645\end{array}$ & $\begin{array}{c}\text { Seconds } \\
\text { of arc } \\
157 \\
108 \\
95.2 \\
76.4 \\
60.1\end{array}$ & $\begin{array}{l}\text { Degrees } \\
-0.0794 \\
-0.0169 \\
-0.0282 \\
-0.0199 \\
-0.0101\end{array}$ & $\begin{array}{c}\text { Degrees } / N_{S} \\
1.375 \times 10^{-3} \\
9.26 \times 10^{-4} \\
7.93 \times 10^{-4} \\
6.47 \times 10^{-4} \\
5.32 \times 10^{-4}\end{array}$ & $\begin{array}{l}\text { Percent } \\
98.0 \\
98.1 \\
98.1 \\
97.9 \\
97.9\end{array}$ & $\begin{array}{c}\text { Seconds } \\
\text { of arc } \\
31.1 \\
20.7 \\
18.4 \\
15.7 \\
12.4\end{array}$ \\
\hline $\begin{array}{r}7 \\
8 \\
9 \\
10 \\
11\end{array}$ & $\begin{array}{l}37 \\
39 \\
40 \\
40 \\
41\end{array}$ & $\begin{array}{l}0.1440 \\
0.1277 \\
0.1150 \\
0.1037 \\
0.0946\end{array}$ & $\begin{array}{l}48.3 \\
40.3 \\
36.0 \\
33.5 \\
32.7\end{array}$ & $\begin{array}{r}-0.0017 \\
+0.0049 \\
+0.0066 \\
-0.0001 \\
-0.0028\end{array}$ & $\begin{array}{l}\text { 4. } 45 \times 10^{-4} \\
\text { 3. } 75 \times 10^{-4} \\
\text { 3. } 30 \times 10^{-4} \\
\text { 3. } 18 \times 10^{-4} \\
\text { 2. } 97 \times 10^{-4}\end{array}$ & $\begin{array}{l}97.7 \\
96.7 \\
96.2 \\
96.5 \\
96.5\end{array}$ & $\begin{array}{r}10.4 \\
10.3 \\
9.9 \\
8.8 \\
8.6\end{array}$ \\
\hline $\begin{array}{l}12 \\
13 \\
14 \\
15 \\
16\end{array}$ & $\begin{array}{l}43 \\
47 \\
47 \\
45 \\
44\end{array}$ & $\begin{array}{l}0.0865 \\
0.0798 \\
0.0737 \\
0.0689 \\
0.0648\end{array}$ & $\begin{array}{l}30.8 \\
28.9 \\
26.7 \\
24.6 \\
22.4\end{array}$ & $\begin{array}{l}-0.0065 \\
-0.0084 \\
-0.0068 \\
-0.0046 \\
-0.0009\end{array}$ & $\begin{array}{l}\text { 2. } 83 \times 10^{-4} \\
\text { 2. } 68 \times 10^{-4} \\
\text { 2. } 45 \times 10^{-4} \\
\text { 2. } 22 \times 10^{-4} \\
\text { 1. } 99 \times 10^{-4}\end{array}$ & $\begin{array}{l}96.3 \\
95.1 \\
94.1 \\
93.6 \\
92.2\end{array}$ & $\begin{array}{l}8.3 \\
9.0 \\
9.0 \\
8.7 \\
8.7\end{array}$ \\
\hline
\end{tabular}

The values of the standard deviations about the prediction or regression lines are plotted in figure 3 along with four values obtained by Bean and Cahoon in their analysis of calculated refraction errors. Direct comparison may be made at 15 degrees and 3 degrees, where the theoretical values are respectively 38 percent and 55 percent of the experimental values. This discrepancy is explained by the assumed accuracy limit of the analysis. Consequently, in the vicinity of 2 degrees, where the standard deviation of refraction exceeds the accuracy limit, agreement is markedly improved.

Furthermore, it is significant that in the Bean and Cahoon analysis the correlation coefficient con-

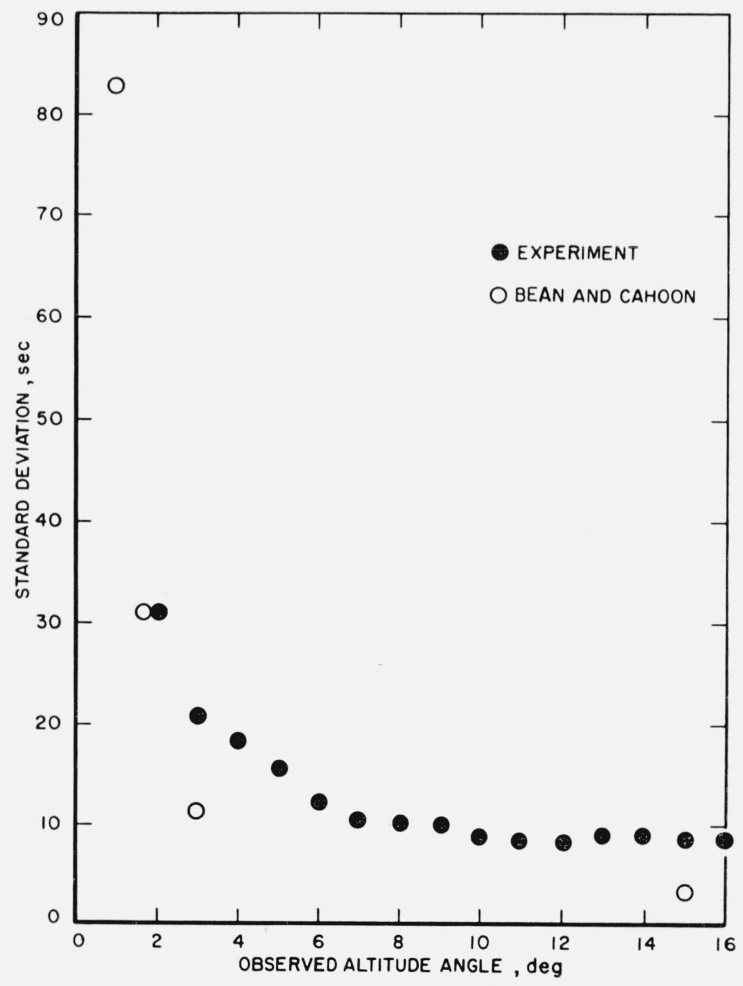

Figure 3. Standard deviation of measured refraction about the regression lines versus observed altitude angle. tinuously increased with altitude angle, while the values in table 1 reach a maximum at 3 degrees and 4 degrees. This disagreement also may be explained by the presence of the analysis accuracy limit, since, with a constant standard deviation about the regression line, the correlation coefficient must reduce as the slope of the line reduces.

\section{Prediction}

The correlation demonstrated in the previous section is of considerable interest in itself, but the application of this correlation in the prediction or estimation of pointing errors produced by refraction is the anticipated result of greatest general interest.

The tabulated regression line slopes and intercepts do not constitute a very convenient formula for prediction. It is desirable to have a continuous empirical function that adequately reproduces the regression line prediction accuracy at the discrete observed altitude angles. An example of this type of empirical predictor is developed in the following paragraphs.

The examined predictor is of the form

$$
\begin{gathered}
\tau=b N_{s}+a \\
a=\frac{-A}{\left(h_{O}+B\right)^{C}} \\
b=\left(\frac{180}{\pi} \times 10^{-6}\right)\left[\cot h_{O}-\frac{D}{\left(h_{O}+E\right)^{F}}\right] .
\end{gathered}
$$

Where $\tau$ is the total refraction or bending angle in degrees, and $a$ and $b$ are functions of the observed altitude angle $\left(h_{o}\right)$ with the dimensions of degrees and degrees per surface refractivity unit respectively. The parameters $\mathrm{A}, \mathrm{B}, \mathrm{C}, \mathrm{D}, \mathrm{E}$, and $\mathrm{F}$ are positive constants to be determined empirically. It is noted that as $h_{o}$ becomes large, $a$ approaches zero and $b$ approaches the product of a constant times the cotangent of the observed altitude angle (or the tangent of the observed zenith angle).

Defining $\Delta b$ by:

$$
\Delta b=b-\left(\frac{180}{\pi} \times 10^{-6}\right) \cot h_{O}
$$

permits careful examination of small departures of $b$ from the simple cotangent form which is entirely adequate at higher observed altitude angles.

When the experimental values of $a$ and $b$, as determined in the regression analysis, are plotted against observed altitude angle as in figures 4 and 5 , it is observed that they oscillate about what might be termed a smooth curve. Further, the oscillations are compensatory, in the sense that positive excursions in $a$ which produce increased $\tau$ values tend to be accompanied by negative excursions in $\Delta b$ which produce decreased $\tau$ values. (See (1) and (5).) $\mathrm{Al}$ though the cause of these oscillations is not readily identifiable, it will be demonstrated later that, whatever their cause, they do little to improve prediction accuracy as compared to smoothed predictors. The 
applicable values of $a$ quoted by Bean and Cahoon also are shown in figure 4 . Fitting (3) to these three values results in the expression

$$
a=\frac{-40}{\left(h_{O}+2.7\right)^{4}}
$$

This expression produces the solid curve of figure 4; the dashed curve represents a fit of (3) to data derived from a supplemental ray-tracing analysis of model atmospheres in a manner similar to that employed by Bean and Cahoon. However, the solid curve not only produces a superior fit to the experimental values, but also permits direct comparison of $b$ values with those of Bean and Cahoon.

Therefore, after defining the intercepts at integral values of $h_{o}$ by (6), the slopes were redetermined by the method of least-squares. The corresponding redetermined $b$ values are shown in figure 5 . It is apparent immediately that the initial oscillations have almost disappeared, and that the agreement with Bean and Cahoon data is excellent.

Fitting the redetermined $b$ values with the empirical expression (4) results in the parameters D, E, and $\mathrm{F}$ shown in the first column of table 2. The second column of the same table indicates the parameters required for a good fit to the three Bean and Cahoon points of figure 5, and the third column displays similar parameters for the supplemental raytracing results. Also shown in the table are the approximate mean values of surface refractivity for the three data groups.

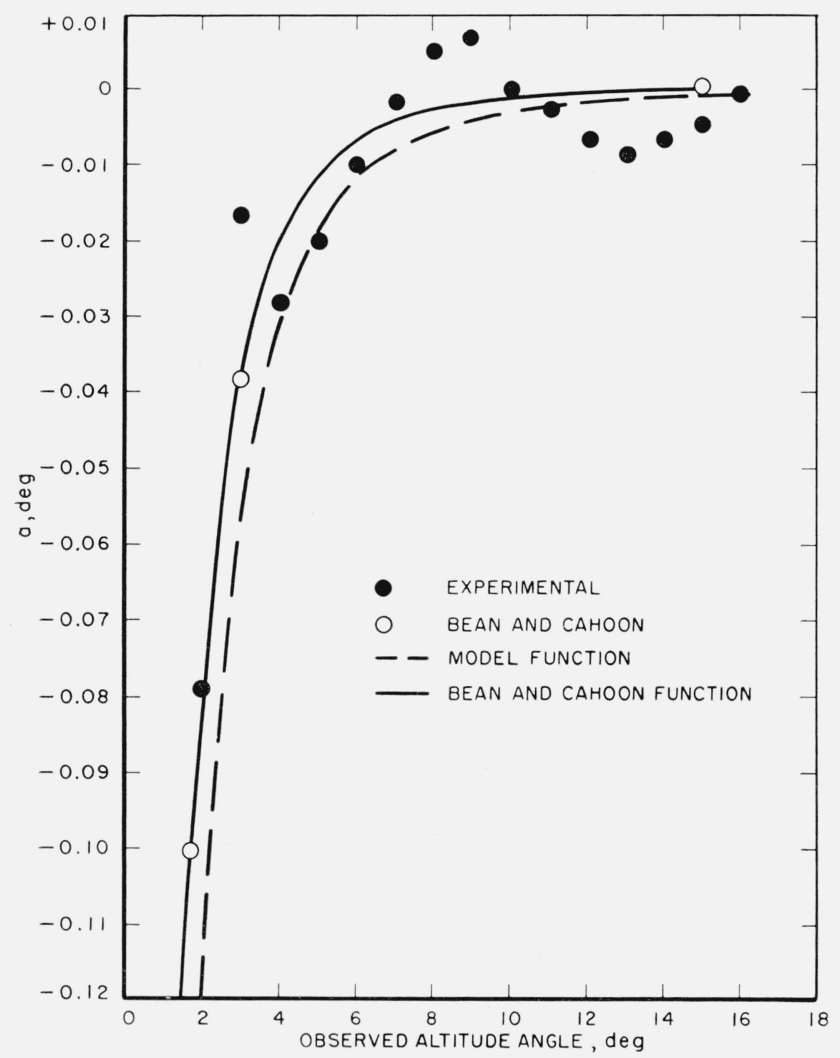

FIGURE 4. Intercept of regression line versus observed altitude angle.

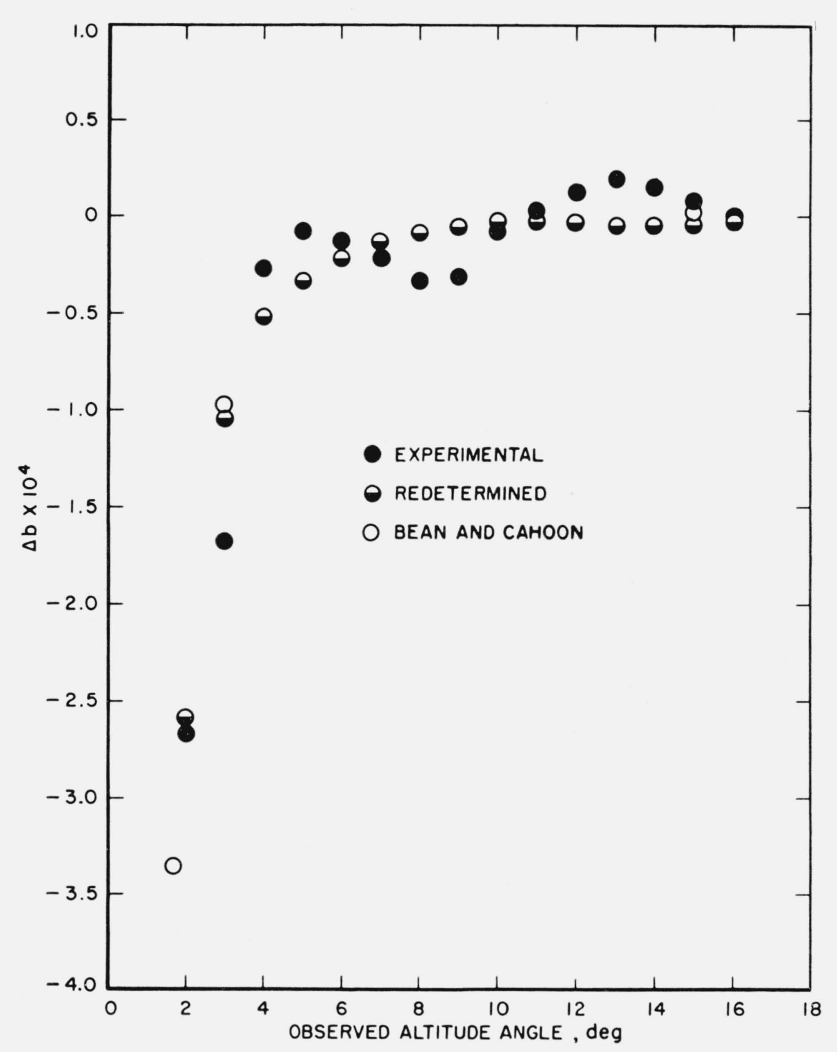

FiguRe 5. Slope of regression line minus $\left(180 \times 10^{-6}\right) \cot h_{0} / \pi$ versus observed altitude angle.

TABLE 2

\begin{tabular}{l|c|c|c}
\hline \hline & $\begin{array}{c}\text { RED } \\
\text { (Redeter- } \\
\text { mined) }\end{array}$ & $\begin{array}{c}\mathrm{BC} \\
\text { (Bean and } \\
\text { Cahoon) }\end{array}$ & $\begin{array}{c}\mathrm{M} \\
\text { (Model) }\end{array}$ \\
\cline { 2 - 3 } & & & \\
$\mathrm{D}$ & 45.6 & 42.5 & 43.0 \\
$\mathrm{E}$ & 0.4 & 0.4 & 0.4 \\
$\overline{\mathrm{F}}$ & 2.64 & 2.64 & 2.69 \\
$\overline{N s}$ & 325 to $330^{*}$ & 334 & 347 \\
& & &
\end{tabular}

${ }^{*}$ In the experiment, the statistics of $N s$ depend upon the observed altitude angle.

A comparison of refraction predicted by the three columns of table 2 and refraction predicted by the regression lines of table 1 (EXP) is given in figure 6 . For an assumed $N_{s}$ of 325 , the value of $\tau_{\text {RED }}$ from the first column of table 2 has been subtracted from the refraction predicted by each of the remaining three over the range of observed altitude angles from 2 to 16 degrees. It is apparent that the combined effect of the oscillations noted in the experimental values of $a$ and $b$ results in prediction discrepancies of less than 0.0012 degree (about 4 seconds of arc) when compared with the empirical predictor, $\tau_{\mathrm{RED}}$ at $N_{s}=325$. It also is evident that $\tau_{\text {RED }}$ satisfactorily averages this oscillatory effect.

It is interesting to note that $\tau_{\mathrm{RED}}, \tau_{\mathrm{BC}}$ and $\tau_{\mathrm{M}}$ exhibit increasingly larger values at each observed altitude angle. This increase is accounted for by an increase in the slope, $b$, because the intercept, $a$, is defined by (6) for each of the three empirical 


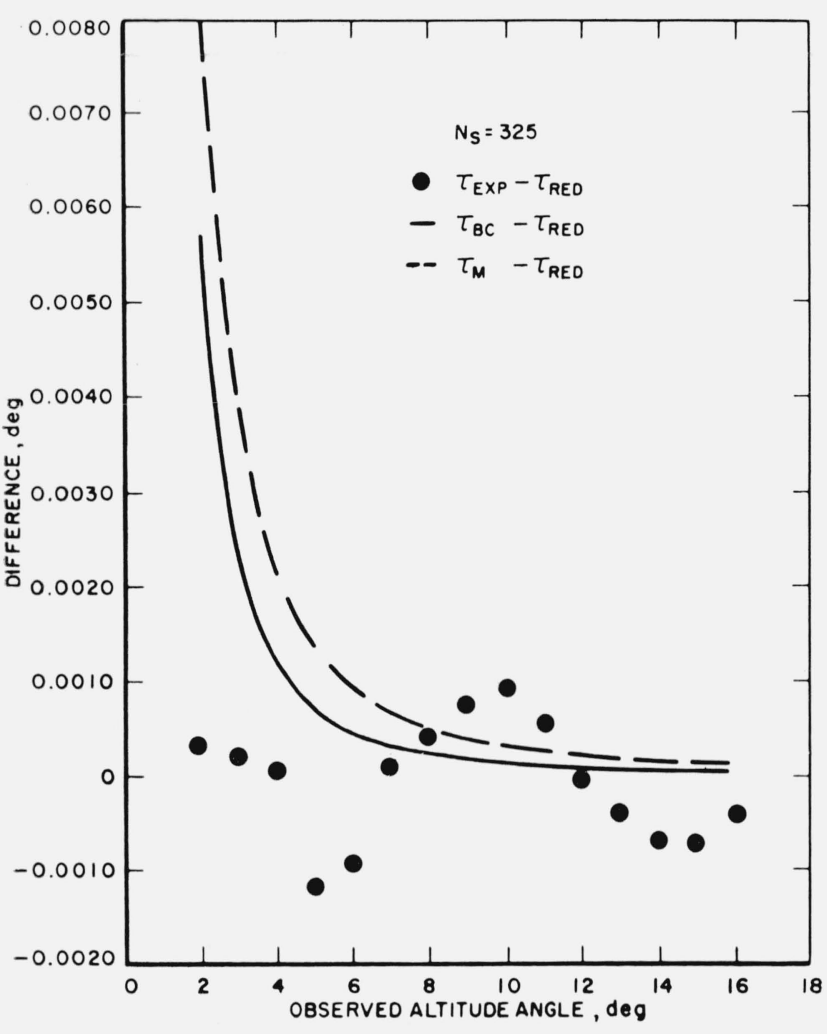

Figure 6. Prediction differences versus observed altitude angle.

predictors. It is reasonable to expect that the exact form of the predictor should depend upon the corresponding mean value of surface refractivity.

A final evaluation of the predictor $\tau_{\mathrm{RED}}$ is illustrated in table 3 . This table compares the standard deviation about the original regression line (as in figure 3) with that about the empirical predictor $\tau_{\text {RED }}$ at each observed altitude angle. It is seen that substitution of the empirical predictor for the original regression lines results in only slight degradation in prediction accuracy.

TABLE 3

\begin{tabular}{|c|c|c|c|}
\hline $\begin{array}{l}\text { Observed } \\
\text { altitude } \\
\text { angle }\end{array}$ & $\begin{array}{l}\text { Standard } \\
\text { deviation } \\
\text { about re- } \\
\text { gression line }\end{array}$ & $\begin{array}{c}\text { Standard } \\
\text { deviation } \\
\text { about pre- } \\
\text { dictor } \tau_{\mathrm{RED}}\end{array}$ & $\begin{array}{l}\text { Increase in } \\
\text { standard } \\
\text { deviation }\end{array}$ \\
\hline $\begin{array}{c}\text { Degrees } \\
2 \\
3 \\
4 \\
5 \\
6\end{array}$ & $\begin{array}{l}\text { Seconds of arc } \\
31.1 \\
20.7 \\
18.4 \\
15.7 \\
12.4\end{array}$ & $\begin{array}{c}\text { Seconds of arc } \\
31.1 \\
22.0 \\
18.7 \\
16.4 \\
12.8\end{array}$ & $\begin{array}{c}\text { Seconds of arc } \\
0 \\
1.3 \\
0.3 \\
0.7 \\
0.4\end{array}$ \\
\hline $\begin{array}{r}7 \\
8 \\
9 \\
10 \\
11\end{array}$ & $\begin{array}{r}1 \mathrm{C} .4 \\
10.3 \\
9.9 \\
8.8 \\
8.6\end{array}$ & $\begin{array}{r}10.4 \\
10.6 \\
10.5 \\
9.4 \\
8.9\end{array}$ & $\begin{array}{l}0 \\
0.3 \\
0.6 \\
0.6 \\
0.3\end{array}$ \\
\hline $\begin{array}{l}12 \\
13 \\
14 \\
15 \\
16\end{array}$ & $\begin{array}{l}8.3 \\
9.0 \\
9.0 \\
8.7 \\
8.7\end{array}$ & $\begin{array}{l}8.5 \\
9.3 \\
9.5 \\
9.1 \\
8.8\end{array}$ & $\begin{array}{l}0.2 \\
0.3 \\
0.5 \\
0.4 \\
0.1\end{array}$ \\
\hline
\end{tabular}

(Paper 67D1-240)

\section{Conclusions}

The use of a precision radio sextant to measure total atmospheric refraction has permitted an experimental verification of the prediction technique suggested by Bean and Cahoon. It has proven the feasibility of improved refraction estimation when only surface meteorological conditions are known.

Although the precision of the measurement technique and subsequent analysis was not sufficient to obtain exact agreement with theory, both the position of the theoretical regression lines and their correlation coefficients have been verified substantially. Further refinements in experimental technique should produce improved agreement with theory.

Fitting polynomials to the original refraction data should have smoothed refraction fluctuations adequately with periods less than one-half hour. The surface refractivity for a given one-half hour segment of each polynomial was estimated from single measurements of meteorological parameters. Thus, measured refraction values were smoothed without a similar smoothing of surface refractivity determinations. Even so, a significant correlation was demonstrated with discrete, uniformly spaced refractivity samples.

It also has been shown that relatively simple empirical expressions may be used to evaluate parameters $a$ and $b$ of (1) at observed altitude angles between 2 and 16 degrees. The nature of the empirical expressions is such that negligible errors are produced if (1) is employed in the range from 16 to 90 degrees.

It is suggested that for maximum accuracy, the parameters of (3) and/or (4) should be adjusted according to the mean value of surface refractivity encountered in a given location during a given period. The predictor best suited to the experimental data presented here is not proposed for general use. Until the nature of this suggested dependence is defined more carefully, the Bean and Cahoon parameters of table 2 probably are more suitable for general prediction.

The authors thank Dr. Gene R. Marner, Director of Research, Collins Radio Company, under whose supervision this work was conducted. Special thanks are due to Mr. A. C. Anway and his coworkers who performed the measurements and assisted in data reduction. This work was supported, in part, by the U.S. Navy Bureau of Naval Weapons, Special Projects Office.

\section{References}

Anway, A. C., Empirical determination of total atmospheric refraction at centimeter wavelengths by radiometric means, J. Research NBS 6rD (Radio Prop.) No. 2 (March-April, 1963).

Bean, B. R., and B. A. Cahoon, The use of surface weather observations to predict total atmospheric bending of radio rays at small elevation angles, Proc. IRE 45, No. 11, 15451546 (Nov. 1959).

Smith, E. K., and S. Weintraub, The constants in the equation for atmospheric refractive index at radio frequencies, Proc. IRE 41, No. 8, 1035-1037 (August 1953). 